\title{
Representative Surface Profile Power Spectra from Capsules used in Nova and Omega Implosion Experiments
}

\author{
R. C. Cook \\ R. L. McEachern \\ This paper was prepared for submittal to the \\ Target Fabrication Meeting '98 \\ Jackson Hole, WY \\ April 19-23, 1998
}

October 20, 1998

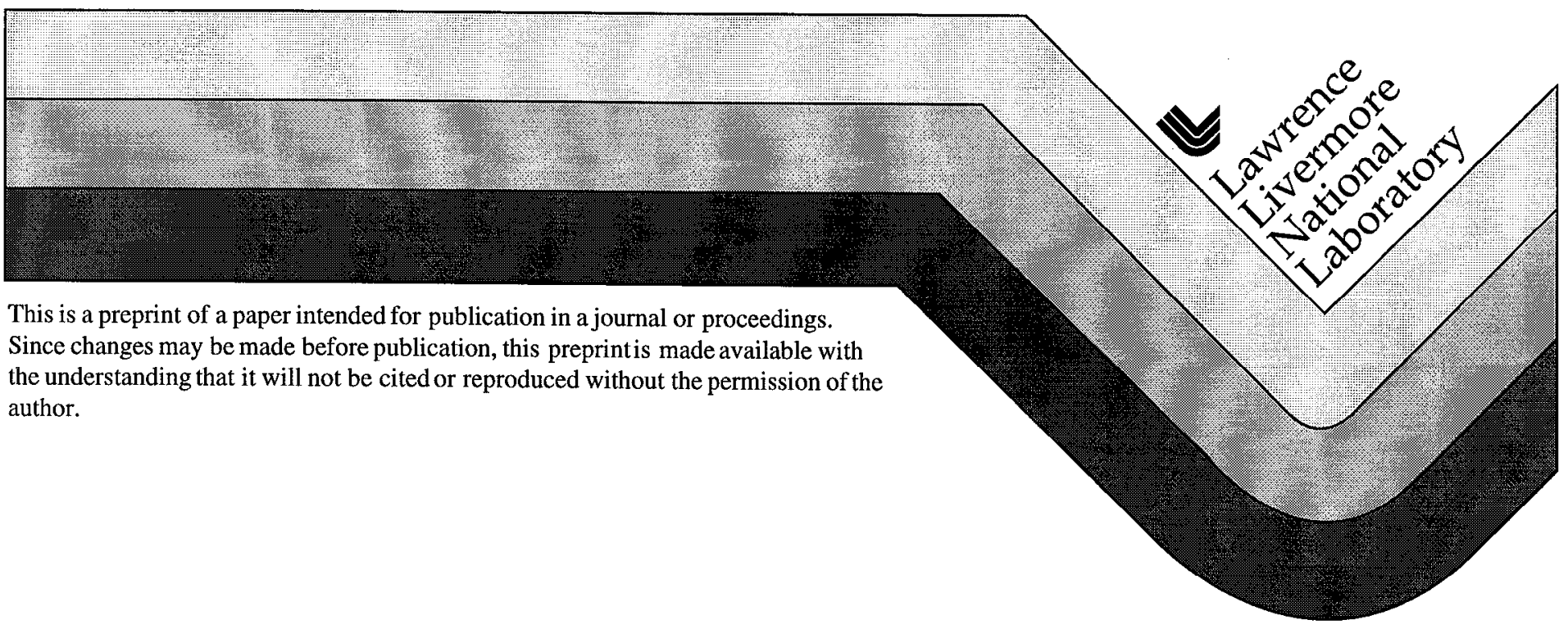




\section{DISCLAIMER}

This document was prepared as an account of work sponsored by an agency of the United States Government. Neither the United States Government nor the University of California nor any of their employees, makes any warranty, express or implied, or assumes any legal liability or responsibility for the accuracy, completeness, or usefulness of any information, apparatus, product, or process disclosed, or represents that its use would not infringe privately owned rights. Reference herein to any specific commercial product, process, or service by trade name, trademark, manufacturer, or otherwise, does not necessarily constitute or imply its endorsement, recommendation, or favoring by the United States Government or the University of California. The views and opinions of authors expressed herein do not necessarily state or reflect those of the United States Government or the University of California, and shall not be used for advertising or product endorsement purposes. 


\section{REPRESENTATIVE SURFACE PROFILE POWER SPECTRA FROM CAPSULES USED IN NOVA AND OMEGA IMPLOSION EXPERIMENTS}

Robert C. Cook and Randall L. McEachern

Lawrence Livermore National Laboratory

Livermore, CA 94551

925-422-3117

\section{ABSTRACT}

Typical surface profile power spectra of capsules used in Nova and Omega implosion experiments are presented. All Nova capsules are essentially identical in size and composition; their differences reflect small shell-to-shell variations. Differences among the Omega capsule power spectra can be attributed to changes in material properties with doping and (very importantly) differences in processing experience. These capsule power spectra accurately reflect past and current production, but are only a starting point for future capabilities.

\section{INTRODUCTION}

In a laser inertial confinement fusion (ICF) experiment, ${ }^{1}$ a small capsule filled with $D_{2}$ or DT is exposed to the energy (drive) from a high powered laser system, symmetrically burning off the capsule's surface in about a nanosecond, thus compressing the fuel to very high densities and temperatures. Under these conditions fusion evẹnts take place.

Experiments of this kind have taken place at the Lawrence Livermore National Laboratory for more than 25 years; since 1985 the 10 beam Nova laser system has been used. At the University of Rochester the recently upgraded 60 beam Omega system has been performing implosion experiments for about 2 years. At either facility, the stability of an ICF implosion depends primarily on symmetry, both in the drive and in the capsule geometry. Particularly important are the surface finish and sphericity of the outside surface of the capsule. To measure this we have developed an AFM-based instrument, the SphereMapper, for mapping the outer surface contour of a capsule. $^{2}$ In this technique the capsule, supported on a vacuum chuck, is rotated while an AFM records the circumferential surface profile. Typically three traces, 40 $\mu \mathrm{m}$ apart, are taken at each of three orthogonal capsule orientations. After correction for capsule offset, each of
Richard B. Stephens

General Atomics

San Diego, CA 92186

619-455-3863

these traces represents the variation of the outer radius as a function of rotational angle, $R(\theta)$. These data can be represented as a Fourier series:

$$
R(\theta)=\sum_{k} A_{k} e^{-i k \theta} .
$$

The square of the amplitude at each $k$ value gives the power at that mode, and the collection of $A_{k}{ }^{2}$, averaged over the nine capsule traces, is the 1-D power spectrum describing the surface finish of the capsule. Assuming isotropy, the 2D surface mode power spectrum can be calculated. ${ }^{2}$ This power spectrum provides the relevant information concerning capsule surface finish for the hydrodynamic codes that calculate capsule performance, allowing comparison with experimental results. Confidence gained here allows one to use these codes in the design of NIF scale capsule targets, including the determination of the allowable surface finish. 1,3

The purpose of this paper is to document the nature of the power spectra obtained from capsules that have been used in Nova experiments over the past 5 years. It is from the $0.5-\mathrm{mm}$ Nova capsule data that the current $2-\mathrm{mm} \mathrm{NIF}$ capsule surface finish design goal has been determined. We will also present the power spectra of the $1-\mathrm{mm}$ capsules used in recent direct drive Omega experiments. Omega capsules are about half way in size to NIF capsules, thus recent Omega capsule roughness data is one indication of our progress toward meeting the NIF requirements.

\section{NOVA CAPSULES}

The data presented here is for $\sim 0.5$-mm-diameter Novascale capsules that were shot (or served as back-ups) on Nova since 1994. These capsules have a $40-$ to $50-\mu \mathrm{m}-$ thick ablator composed of a CH-based plasma polymer, ${ }^{4}$ sometimes called glow discharge polymer (GDP), which is generally doped with a small amount of $\mathrm{Ge}^{5}$ About 60 capsule power spectra were examined, of which 51 had rms 


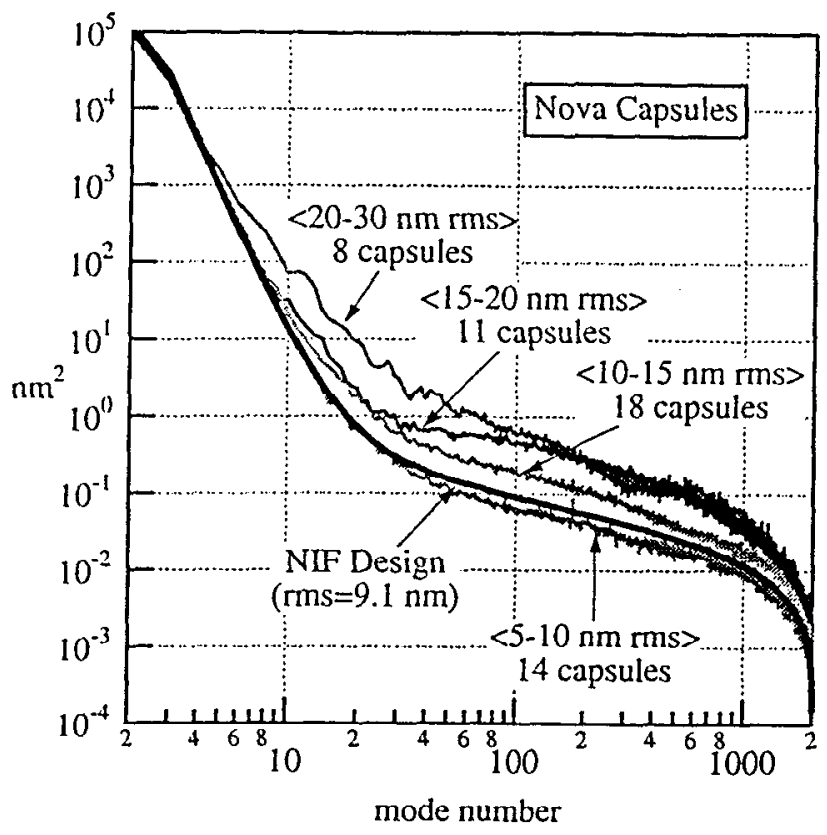

Figure 1. Shown are the average power spectra for each grouping of Nova capsules. For comparison the smooth trace is the NIF design specification. In an average sense the groups show progressively more roughness at all modes even though the groupings are dominated by the power between modes 10 and 20 .

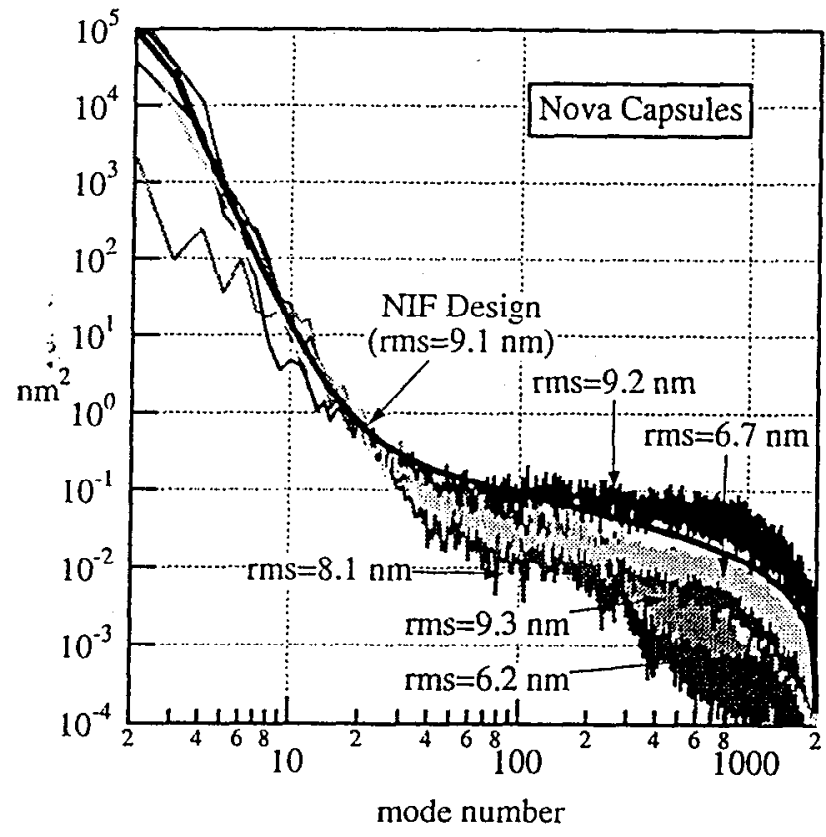

Figure 2. Shown in shades of gray are the power spectra for 5 Nova capsules that have a rms over modes 10 to 1000 of less than $10 \mathrm{~nm}$. As in Fig. 1, the smooth black trace is the NIF design specitication. Clearly seen is the broad range of surface roughness at higher mode numbers exhibited by this (and each other) group.
Table I. Roughness $\mathrm{rms}(\mathrm{nm})$ range as a function of mode number for the capsule groups displayed in Fig. 1.

\begin{tabular}{lrrrr} 
& \multicolumn{4}{c}{ rms (nm) modes 10-1000 } \\
\cline { 2 - 5 } mode(s) & 5 to 10 & 10 to 15 & 15 to 20 & 20 to 30 \\
\hline 2 & $49-460$ & $101-500$ & $89-724$ & $67-583$ \\
$10-20$ & $4.0-8.5$ & $4.2-12.1$ & $6.3-15.5$ & $10.4-24.0$ \\
$20-100$ & $2.4-5.4$ & $2.9-8.5$ & $5.6-10.5$ & $3.4-17.4$ \\
$100-1000$ & $1.8-7.4$ & $2.7-11.0$ & $6.6-15.6$ & $4.8-19.8$ \\
$1000-2000$ & $0.3-4.2$ & $10-5.3$ & $2.3-6.5$ & $1.6-6.9$ \\
\hline
\end{tabular}

(modes $>10$ ) surface finishes of less than $30 \mathrm{~nm}$. The statistics for these shells are presented here. No attempt was made to examine all shells shot, but we feel that the shell data presented here are representative of "smooth capsules." 28 of the capsules date from 1994 and 1995, the remainder from 1996 and 1997.

The capsule power spectra were sorted by rms over modes 10 to 1000 into 4 groups, those with rms less than $10 \mathrm{~nm}, 10$ to $15 \mathrm{~nm}, 15$ to $20 \mathrm{~nm}$, and 20 to $30 \mathrm{~nm}^{2}$ A comparison of older and more recent capsule power spectra showed there to be no significant improvement in capsule surface finish during this period although there were numerous changes in fabrication techniques. Of the 14 capsules with rms surface finishes less than $10 \mathrm{~nm}$, half are from 1994-5 and half from 1996-7. It should be emphasized that this comparison concerns only the outer surface power spectra and not other areas such as concentricity $\left(P_{1}\right.$ defect) where there have been improvements. In addition, since this study examined only those capsules actually shot, it does not speak to possible increased yields of high quality ("shootable") capsules.

Plotted in Fig. 1 are average power spectra for each of the groups noted above. Although the sorting is dominated by the power in the lowest modes ( 10 to 20 ) it is worth noting that on average the rougher capsules are rougher at all modes. Figure 2 shows the individual spectra for five of the capsules with a surface roughness over modes 10 to 1000 of less than $10 \mathrm{~nm}$. Although these are clustered tightly at modes 10 to 20 , at modes greater than 30 there are significant differences in the surface roughness. For this reason the simple characterization of the capsule surface roughness by a single rms value provides only limited information. Note also that one of the capsules ( $\mathrm{rms}=9.3$ $\mathrm{nm}$ ) has exceptionally low power at modes less than 10 .

\footnotetext{
a The choice to sort by rms over modes 10 to 1000 was largely arbitrary. The exclusion of the lower modes was primarily motivated by the large variation in the rms contribution from these modes, as evidenced by the data reported for mode 2 in Table I.
} 
The roughness in this range is dominated by the basic mode 2 out-of-round amplitude, in this case about $0.05 \mu \mathrm{m}$ (50 $\mathrm{nm}$ ), much less than the more typical 0.3 to $0.4 \mu \mathrm{m}$ for these capsules. Table $I$ expands upon this analysis by reporting the range of $\mathrm{rms}$ values for specific modal intervals for each grouping of capsules. While the general trend that rougher capsules are rougher at all modes (comparisons along a line of the table) in an average sense is clear from Fig. 1, it is also clear that individual capsules can have significantly different roughnesses at high mode numbers which have very little effect on the net mode 10 to 1000 capsule rms.

In concluding this section we point out the smooth curves in Figs. 1 and 2 labeled "NIF Design." This is the power spectrum being used by the designers to model the exterior surface finish of capsules for various NIF target designs, and thus represents a goal for those currently developing the technology for the production of NIF capsules. As can be seen in Fig. 1, the NIF Design power spectrum is essentially a fit to the average power spectrum of the best Nova capsules produced. As such it represents a difficult challenge for capsule fabricators. At $2 \mathrm{~mm}$ in diameter the NIF capsule is four times larger than a Nova capsule. If all features of a Nova capsule were simply magnified by a factor of four, the power at each mode number would grow by a factor of 16 , shifting the $<5-10$ $\mathrm{nm}$ rms $>$ power spectrum up by more than a decade, significantly above the NIF design, thus requiring significant improvement in existing technology.

The scaling described above is an oversimplification, however. At high mode number the roughness of the capsule is due entirely to the coating technology used to apply the capsule ablator to the underlying mandrel. Thus in the case of a Ge-doped GDP coated NIF capsule we might expect at high mode numbers that the current technology would give similar absolute roughness ${ }^{b}$ to what is found on Nova capsules, perhaps degraded slightly because of the thicker coating. ${ }^{6}$ In fact, the preferred ablator materials for the NIF capsule are either $\mathrm{Cu}$-doped $\mathrm{Be}$ or polyimide, ${ }^{7}$ neither of which has been used for Nova capsules. Thus a major goal of the development of these technologies is the capability to deposit smooth coatings. Aspects of this work are described in this issue ${ }^{8}$ and elsewhere. 9

\footnotetext{
b Roughness features of equal size on a Nova and NIF capsule are manifested differently in their power spectra because of the diameter difference. A feature that gives rise to power $P$ at mode $k$ on a Nova capsule would appear with power $P / 4$ at mode $4 k$ on a NIF capsule.
}

At low mode numbers the surface finish is largely dominated by the sphericity of the underlying mandrel upon which the ablator is applied, assuming the ablator coating process does not cause capsule deformations. Producing adequately spherical mandrels may in fact be the most challenging problem, since here the asphericity generally scales with capsule size to some power for the solution techniques currently being pursued. ${ }^{10}$ Progress has been encouraging, however. Details can be found elsewhere in this issue. ${ }^{11}$

\section{OMEGA CAPSULES}

Unlike the earlier Nova drop-tower shells, ${ }^{12}$ the mandrels for the Omega capsules are made by the poly $(\alpha-$ methylstyrene) (P $\alpha$ MS) based decomposable mandrel technique developed by Letts. ${ }^{13}$ In addition, the permeation

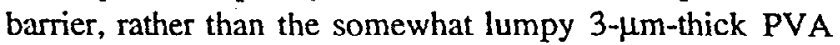
layer used for Nova capsules, ${ }^{12}$ is in these shells a smooth $0.1-\mu \mathrm{m}$-thick aluminum layer. As a result, the roughness mechanisms, and the resulting roughness power spectra, are somewhat different than those of Nova capsules. The base roughness is set by the initial PaMS mandrel, which, in the best of circumstances, is replicated on the surface of the GDP shell made from it. But handling, thickness, and doping all contribute to additional roughness on the final target.

Also unlike the Nova shells, there is no standard 'vanilla' shell. The Omega target configurations have been widely different and no single variety dominates. For this paper, we have divided the targets into 4 groups and show representative power spectra for each group in Figs. 3-6. The diameters of all the shells are 0.9 to $1.0 \mathrm{~mm}$. The shell walls vary from 3-50 $\mu \mathrm{m}$, and can be undoped or Gedoped GDP, and can include $1-\mu \mathrm{m}$-thick layers of titaniumor deuterium-doped GDP within a thicker layer. Each of these groups shows distinctive power spectra indicative of the particular mix of defects present on those surfaces.

In production, each of the variations had distinct problems, and for each, the production process had to be reoptimized to produce acceptable shells. As a result, the differences between the groups do not reflect ultimate process limits, but are more indicative of the amount of experience with a given configuration. As an example, the high-mode-number roughness in the power spectra of the plain GDP and Ge-GDP shells (Figs. 3 and 4) is caused by a high concentration of small domes on the surface. Recent studies have shown that such domes were the result of collisions between shells during the GDP coating process if the coating pan was crowded (> 50 1-mm shells). As it happened, $\sim 70$ shells were put in the coating pan for each of those runs, while less than 20 were used for most of the 
other runs. Since then, a procedure in which the shells are rolled rather than bounced has been developed, and the problem of domes from collisions in crowded coating pans has been eliminated. ${ }^{14}$ Future target power spectra are expected to be more nearly like those shown in Figs. 5 and 6 than Figs. 3 and 4.

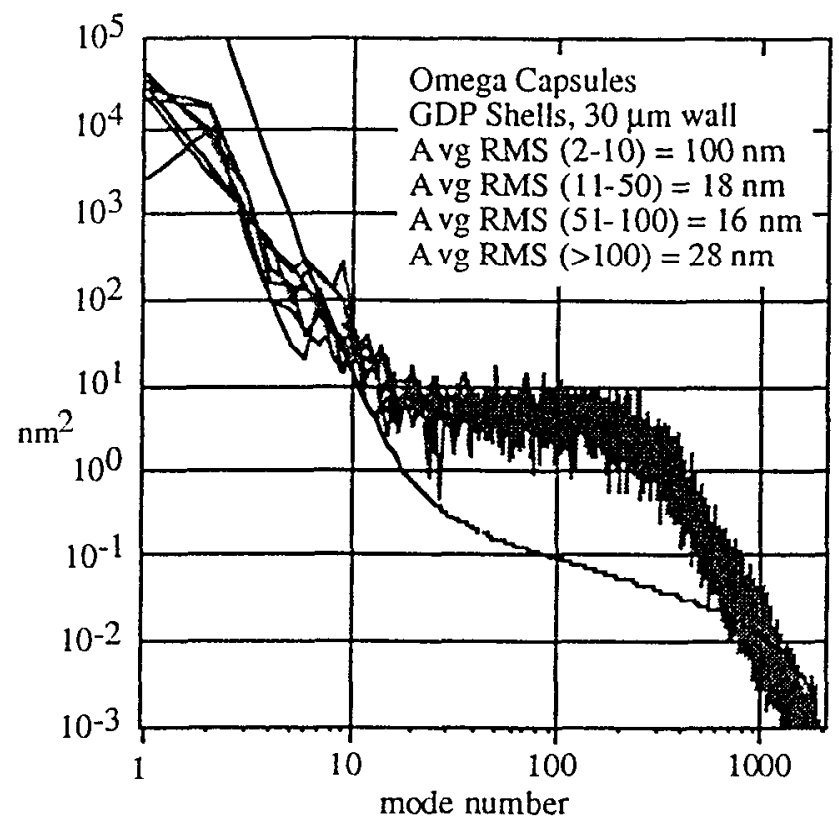

Figure 3. Shown are power spectra from several Omegascale undoped GDP capsules produced in late 1996.

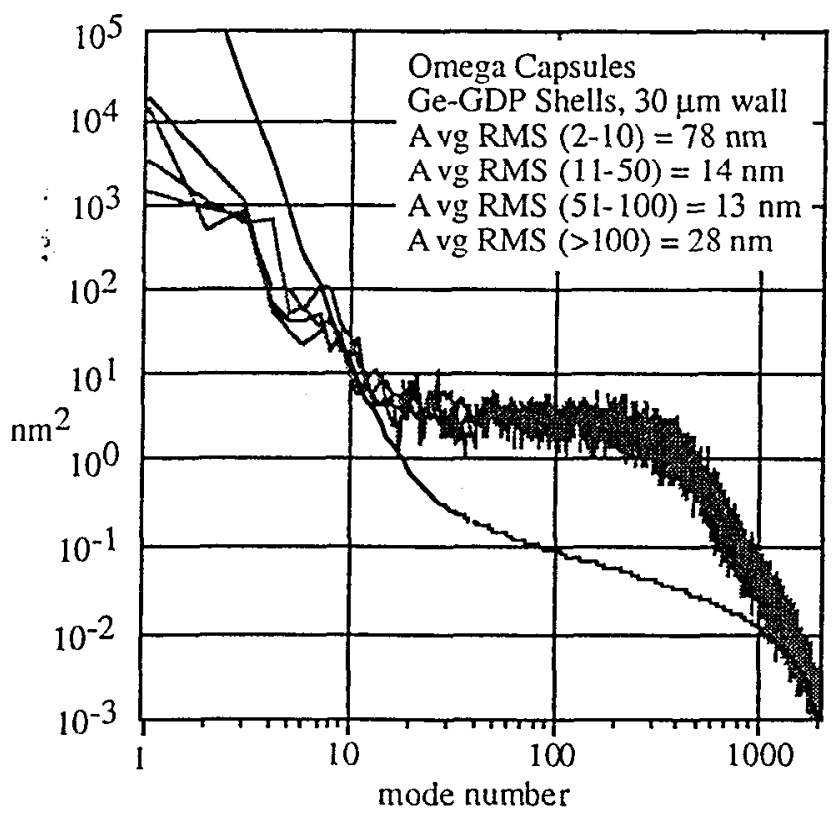

Figure 4. Shown are power spectra from several Omegascale Ge-doped GDP capsules produced in late 1996.

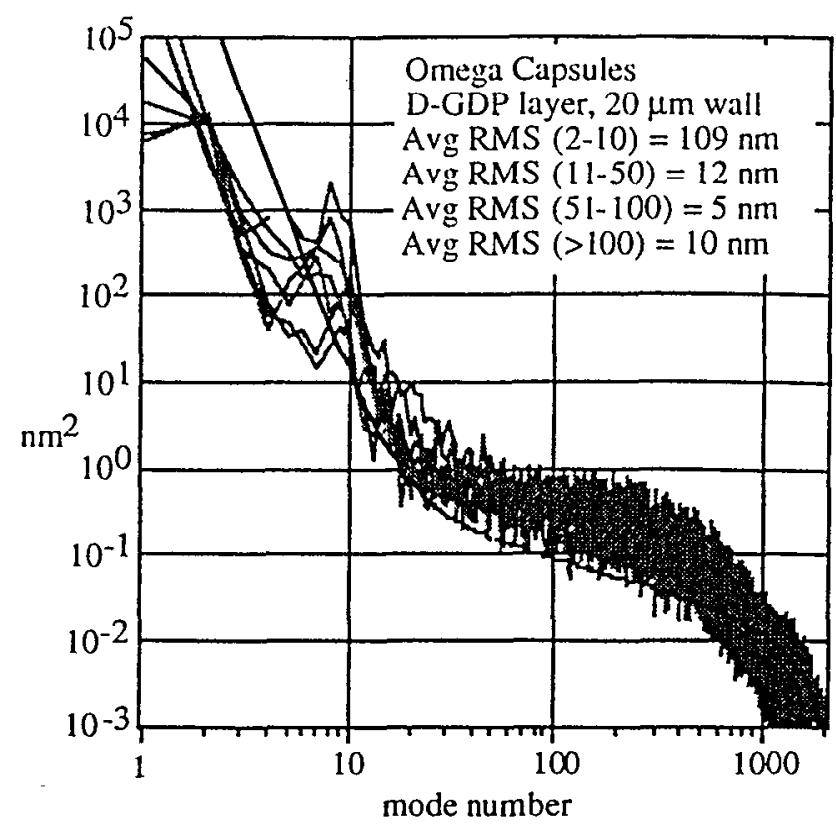

Figure 5. Shown are power spectra from several Omegascale capsules produced between mid-1996 and mid-1997 with a $1-\mu \mathrm{m}$-thick $D$-doped GDP layer sandwiched by plain GDP, and a total wall thickness of $20 \mu \mathrm{m}$. The peak at mode $\sim 8$ is caused by the P $\alpha$ MS mandrel on which these shells were made.

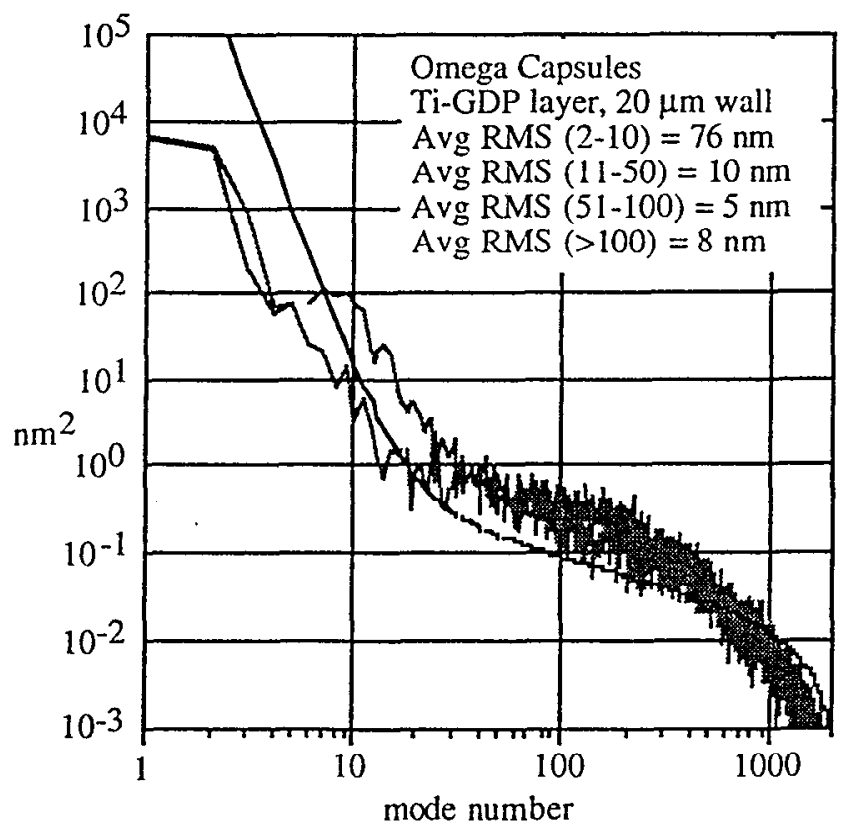

Figure 6. Shown are power spectra for two Omega-scale capsules produced in mid-1996 with a $1-\mu \mathrm{m}$-thick Ti-doped GDP layer sandwiched by plain or Cl-doped GDP, and a total wall thickness of $20 \mu \mathrm{m}$. 


\section{ACKNOWLEDGMENTS}

The authors thank Craig Moore and Evelyn Fearon at LLNL, and David Steinman at GA, who performed the sphere-maps and processed the data discussed in the this paper. This work was performed under the auspices of the U. S. Department of Energy by the Lawrence Livermore National Laboratory under Contract W-7405-ENG-48 and by General Atomics under Contract DE-AC03-95SF20732.

\section{REFERENCES}

1. J. Lindl, "Development of the Indirect-Drive Approach to Inertial Confinement Fusion and Target Physics Basis for Ignition and Gain," Phys. Plasmas 2, 3933 (1995).

2. R. L. McEachern, C. E. Moore, and R. J. Wallace, "The Design, Performance, and Application of an Atomic Force Microscope-Based Profilometer," J. Vac. Sci. Technol. A 13, 983 (1995).

3. S. W. Haan, et al., "Design and Modeling of Ignition Targets for the National Ignition Facility," Phys. Plasmas 2, 2480 (1995).

4. S. A. Letts, D. W. Myers, L. A. Witt, "Ultrasmooth Plasma Polymerized Coatings for Laser Fusion Targets," J. Vac. Sci. Technol. 19, 739 (1981).

5. R. Brusasco, M. Saculla, and R. Cook, "Preparation of Germanium Doped Plasma Polymerized Coatings as Inertial Confinement Fusion Target Ablators," J. Vac. Sci. Technol. A 13, 948 (1995).

6. G. W. Collins, S. A. Letts, E. M. Fearon, R. L. -McEachern, and T. P. Bernat, "Surface Roughness Scaling of Plasma Polymer Films," Phys. Rev. Lett. 73, 708 (1994).

7. T. R. Dittrich, et al., "NIF Capsule Design Update," Fusion Technol. 31, 402 (1997); M. M. Marinak, et al., "A Comparison of Three-Dimensional Multimode Hydrodynamic Instability Growth on Various National Ignition Facility Capsule Designs with HYDRA Simulations," Phys. Plasmas 5, 1125 (1998); D. C. Wilson, et al., "The Development and Advantages of Beryllium Capsules for the National Ignition Facility," Phys. Plasmas 5, 1953 (1998); and T. R. Dittrich, et al., "Reduced Scale National Ignition Facility Capsule Design," Phys. of Plasmas 5, 3708 (1998).
8. See the following papers in this issue on beryllium ablator technology: R. McEachem and C. Alford, "Evaluation of Boron-doped Beryllium as an Ablator for NIF Target Capsules," and R. W. Margevicius, et al., "Toward the Fabrication of a NIF Target via Hemisphere Joining." For polyimide ablator technology see: E. Alfonso, et al., "Fabrication of Polyimide Shells by Vapor Phase Deposition for Use as ICF Targets," and C. Roberts, et al., "Polyimide Films from Vapor Deposition: Toward High Strength NIF Capsules."

9. R. McEachern, C. Alford, R. Cook, D. Makowiecki, and R. Wallace, "Sputter-Deposited Be Ablators for NIF Target Capsules," Fusion Technol. 31, 435 (1997); E. L. Alfonso, S. H. Chen, R. Q. Gram, D. R. Harding, J. of Mater. Res. 13, 2988 (1998).

10. R. C. Cook, P. M. Gresho, and K. E. Hamilton, "Examination of Some Droplet Deformation Forces Related to NIF Capsule Sphericity," J. Moscow Phys. Soc., (1998), in press. Also see in this issue P. M. Gresho, "Some Aspects of the Hydrodynamics of the Microencapsulation Route to NIF Mandrels."

11. See the following papers in this issue: B. McQuillan and A. Greenwood, "Microencapsulation Process Factors Which Influence the Sphericity of $1 \mathrm{~mm}$ O.D. Poly ( $\alpha$-Methylstyrene) Shells for ICF," B. McQuillan, et al., "The Use of $\mathrm{CaCl}_{2}$ and Other Salts to Improve Surface Finish and Eliminate Vacuoles in ICF Microencapsulated Shells," and R. Cook, et al., "New Approaches to the Preparation of P $\alpha$ MS Beads as Mandrels for NIF-Scale Target Capsules."

12. R. Cook, "Production of Hollow Microspheres for Inertial Confinement Fusion Experiments," Mat. Res. Soc. Symp. Proc. 372, 101 (1995).

13. S. A. Letts, E. M. Fearon, S. R. Buckley, M. D. Saculla, L. M. Allison, and R. Cook, "Fabrication of Polymer Shells Using a Decomposable Mandrel," Fusion. Technol. 28, 1797 (1995). See also B. W. McQuillan, A. Nikroo, D. A. Steinman, F. H. Elsner, D. G. Czechowicz, M. L. Hoppe, M. Sixtus, and W. J. Miller, "The PAMS/GDP Process for Production of ICF Target Mandrels," Fusion Technol. 31, 381 (1997).

14. See in this issue A. Nikroo and D. Woodhouse, "Bounce Coating Induced Domes on Glow Discharge Polymer Coated Shells." 
. 